\title{
RPUDD
}

絭

Revista Pedagogía Universitaria y Didáctica del Derecho

Primer Semestre, año 2017.

Volumen 4, número 1.

La Revista Pedagogía Universitaria y Didáctica del Derecho es una publicación de la Unidad de Pedagogía Universitaria y Didáctica del Derecho, de la Facultad de Derecho de la Universidad de Chile. Es una publicación internacional, con trabajo conjunto entre Chile y Brasil. La Revista tiene por objetivo central configurarse como un espacio académico de encuentro entre investigadores, abogados y expertos en educación (licenciados en educación, profesores, psicólogos educacionales y sociólogos de la educación) a propósito de la investigación sobre pedagogía universitaria, docentes universitarios, estudiantes universitarios, enseñanza-aprendizaje del derecho, prácticas docentes, profesión jurídica y currículo.

Revista Pedagogía Universitaria y Didáctica del Derecho En línea. Coodirección

Chile Dra. María Francisca Elgueta. Brasil Dr. Renato Duro Dias. ISSN 0719-5885 rpedagogia@derecho.uchile.cl +5629785397

Algunos derechos reservados. Publicada bajo los términos de la licencia Creative Commons atribución - compartir igual 4.0 internacional. 


\section{APRENDIZAJ E BASADO EN PROBLEMAS: METODOLOGÍA DIDÁCTICA PARA ABORDAR LA ASIGNATURA DE DERECHO PROCESAL CIVIL}

\section{Problem-based learning: teaching methodology applied to a Civil Procedural Law course}

Patricia Ramírez Ortiz ${ }^{1}$

Ignacio Luna Espinoza ${ }^{2}$

Resumen: En este trabajo se expone la forma en la que se ha implementado la técnica del Aprendizaje Basado en Problemas en la asignatura de Derecho Procesal Civil, en el quinto semestre de la licenciatura en Derecho en la Universidad del Istmo, México. Partiendo de un problema jurídico, describimos la forma en la que se han llevado a cabo

1 Abogada. Maestra en Derecho por la Universidad Nacional Autónoma de México. Profesora-investigadora en la Universidad del Istmo campus Ixtepec, Oaxaca, México. Correo institucional: patricia-rmz@bianni.unistmo.edu.mx

2 Maestro en Ciencias en Estadística por el Colegio de Postgraduados, México. ProfesorInvestigador en la Universidad del Istmo campus Ixtepec, Oaxaca, México. Correo institucional: iluna@bianni.unistmo.edu.mx

DOI: 10.5354/0719-5885.2017.46254

Fecha de recepción 28 abril 2016.

Fecha aceptación 07 de julio 2016. 
REVISTA PEDAGOGÍA UNIVERSITARIA Y DIDÁCTICA DEL DERECHO [ISSN 0719-5885]

Unidad de Pedagogía Universitaria y Didáctica del Derecho, Universidad de Chile

$\mathrm{N}^{\circ}$ 1, vol. 4, $1^{\circ}$ semestre de 2017, 189-224 pp.

todas las etapas del juicio para llegar a una sentencia definitiva; proceso en el que el trabajo en equipo y la participación activa de los estudiantes es indispensable. También se muestra la opinión de las alumnas y alumnos sobre la aplicación de esta metodología en su proceso de aprendizaje.

Palabras Clave: Aprendizaje Basado en Problemas, Metodología didáctica, Derecho Procesal Civil.

Summary: This paper describes how the technique of Problem-based Learning has been implemented among fifth semester undergraduate students enrolled in civil procedural law at the University of the Isthmus, Mexico. Based on a legal problem, we describe how all the stages of a trial are carried out in order to finally reach a final judgment; a process in which teamwork and an active student's participation are indispensable. In addition, the student's views on the application of this methodology in the learning process are explained.

Keywords: Problem-based learning, Teaching methodology, Civil procedure.

\section{Introducción}

La crítica más constante que se hace al modelo de enseñanza tradicional es el aspecto memorístico que predomina, pues vuelve al alumno un sujeto pasivo y mero receptor de información que después tiene que reproducir en un examen. En México, en el proceso de formación jurídica este paradigma educativo continúa hasta nuestros días. Como la aptitud que se prioriza es la 
REVISTA PEDAGOGÍA UNIVERSITARIA Y DIDÁCTICA DEL DERECHO [ISSN 0719-5885]

Unidad de Pedagogía Universitaria y Didáctica del Derecho, Universidad de Chile

$\mathrm{N}^{\circ}$ 1, vol. 4, $1^{\circ}$ semestre de 2017, 189-224 pp.

memorización mecánica, se enseña a repetir conceptos, procesos, procedimientos y normas jurídicas. Los contenidos de las materias tienen una función más informativa y su estudio generalmente se hace de forma aislada de otras ramas del derecho y de otras disciplinas.

Para tratar de superar este tipo de prácticas escolares, en la Universidad del Istmo, en el estado de Oaxaca, México, se ha implementado la técnica del Aprendizaje Basado en Problemas (ABP) a la materia de Derecho Procesal Civil (DPC), la cual se imparte en el quinto semestre de la licenciatura en Derecho ${ }^{3}$. El programa de estudios de la asignatura de DPC señala como objetivos generales: conocer, analizar, explicar y dominar los aspectos teóricos y prácticos de esta rama del derecho, a fin de interpretar y aplicar correctamente el Código de Procedimientos Civiles para el Estado de Oaxaca (CPCEO) a casos concretos en la práctica profesional; y lograr la adecuada interpretación y aplicación supletoria del Código Federal de Procedimientos Civiles (CFPC) a casos concretos en la práctica profesional. La materia está programada en doce temas, los cuales son abordados en un promedio de 85 horas-clases, más las horas extra clase necesarias. Además, de acuerdo a las reglas universitarias, conforme avanza el curso, este debe evaluarse con tres exámenes parciales y un examen ordinario.

Con la incorporación del ABP se buscó que los alumnos desarrollaran un caso en el que integraran conocimientos previos de materias como Derecho Civil I, II y III y teoría general del proceso, entre otras. También se promovió el análisis e interpretación de los códigos mencionados en el párrafo anterior, así como el desarrollo de las habilidades de comunicación escrita y verbal para con una autoridad jurisdiccional. Esto se hizo mediante la elaboración de diversos documentos en los que se procuró que los estudiantes conocieran la

${ }^{3}$ En la Universidad del Istmo, la licenciatura en Derecho se cursa en diez semestres. 
REVISTA PEDAGOGÍA UNIVERSITARIA Y DIDÁCTICA DEL DERECHO [ISSN 0719-5885]

Unidad de Pedagogía Universitaria y Didáctica del Derecho, Universidad de Chile

$\mathrm{N}^{\circ}$ 1, vol. 4, $1^{\circ}$ semestre de 2017, 189-224 pp.

estructura de una promoción (demanda, contestación a la demanda, ofrecimiento de pruebas) y la estructura de una resolución (auto, sentencia). Además, se vigiló que los alumnos analizaran la pertinencia de lo que argumentaban y fundamentaban, así como la congruencia de su estrategia de prueba acorde a su rol de parte actora o parte demandada.

\section{Aprendizaje basado en problemas}

El ABP se implementó por primera vez en la década de 1960 en la facultad de medicina de la universidad canadiense de McMaster ${ }^{4}$. Como la educación médica en esa institución se caracterizaba por una serie de clases expositivas de ciencia básica y de un programa de enseñanza clínica, sus educadores médicos visualizaron la necesidad de preparar a los estudiantes para que enfrentaran el crecimiento sin precedentes de la información médica, las nuevas tecnologías, las demandas cambiantes de la práctica profesional y, principalmente, adquirieran habilidades para solucionar problemas 5 . En este escenario, en la Universidad de McMaster se diseñó e implementó una propuesta educacional conocida actualmente como $\mathrm{ABP}^{6}$.

Desde su gestación, en la década de 1960, la implementación del ABP en diversas universidades del mundo ha crecido significativamente. Así, por ejemplo, en la década de 1970 se implementó en las universidades de

4 J oanne Clough \& Gillian W. Shorter, "Evaluating the effectiveness of problem-based learning as a method of engaging year one law students", Law Teacher 49, n. ${ }^{\circ} 3$ (2015): 277302.

5 Patricia Morales y Victoria Landa, “Aprendizaje Basado en Problemas”, Theoria 13, n. 1 (2004): 145-157.

${ }^{6}$ Howard Barrows, "Problem-Based learning in medicine and beyond: A brief overview". New Directions For Teaching And Learning 68 (1996): 3-12 
REVISTA PEDAGOGÍA UNIVERSITARIA Y DIDÁCTICA DEL DERECHO [ISSN 0719-5885]

Unidad de Pedagogía Universitaria y Didáctica del Derecho, Universidad de Chile

$\mathrm{N}^{\circ}$ 1, vol. 4, $1^{\circ}$ semestre de 2017, 189-224 pp.

Michigan (Estados Unidos), Maastricht (Holanda), Newcastle (Australia) y en la década de 1980 en la Universidad de Nuevo México (Estados Unidos). Más tarde, diversas facultades de universidades, como las de Hawái, Harvard y Sherbrooke, reestructuraron sus programas curriculares para dar cabida al $\mathrm{ABP}^{7}$. En la actualidad, decenas de universidades en el mundo han adoptado exitosamente esta metodología educacional, principalmente en facultades de medicina ${ }^{8}$.

Pero, ¿qué es el $\mathrm{ABP}$ ? Originalmente el $\mathrm{ABP}$ se concibió como un método de aprendizaje que usaba problemas reales para adquirir nuevos conocimientos. Sin embargo, la concepción del ABP ha evolucionado no sólo por la integración de nuevos conocimientos, sino por las diversas disciplinas que la han adoptado ${ }^{9}$. Actualmente, varios autores, como Rue, Font y Cebrian, consideran que el $\mathrm{ABP}$ es más que una metodología constructivista pues se nos presenta como una filosofía, como una forma de entender la educación y como un estilo de aprender ${ }^{10}$.

El ABP es una metodología didáctica constructivista que busca el aprendizaje por medio de la resolución de un problema. Frida Díaz Barriga lo define como una experiencia pedagógica de tipo práctica y organizada para investigar y resolver problemas vinculados al mundo real, la cual fomenta el

7 Barrows, "Problem-Based learning in medicine and beyond".

8 Cindy Hmelo-Silve, "Problem-based learning: what and how do students learn?", Educational Psychology Review 16, n. 3 (2004): 235- 266.

9 Morales y Landa, “Aprendizaje basado en problemas”, 145-157.

10 J oan Rué Domingo et al., "El ABP, un enfoque estratégico para la formación en educación superior. Aportaciones de un análisis de la formación en derecho", REDU: Revista de Docencia Universitaria 9, $\mathrm{n}^{\circ} 1$ (2011): 25-44. 
REVISTA PEDAGOGÍA UNIVERSITARIA Y DIDÁCTICA DEL DERECHO [ISSN 0719-5885]

Unidad de Pedagogía Universitaria y Didáctica del Derecho, Universidad de Chile

$\mathrm{N}^{\circ}$ 1, vol. 4, $1^{\circ}$ semestre de 2017, 189-224 pp.

aprendizaje activo e integra el aprendizaje escolar con la vida real, por lo general desde una mirada multidisciplinar ${ }^{11}$.

De acuerdo a Carlos Sola Ayape, los pasos del $\mathrm{ABP}^{12}$ son: a. Presentación y lectura comprensiva del escenario, b. Definición del problema, c. Lluvia de ideas, d. Clasificación de las ideas, e. Objetivos de aprendizaje, f. Investigación, y g. Presentación y discusión de los resultados.

Por otro lado, de acuerdo a Cortés Marín, la verdadera gestación del ABP se remonta en el ámbito jurídico con el método del caso iniciado en la facultad de derecho de la Universidad de Harvard en 1870, pues es precisamente en este año cuando se inició la formación de estudiantes a través de fallos jurisprudenciales reales que trataban como ejemplos de práctica de donde los estudiantes debían extraer e inducir los principios generales. Esta forma de enseñanza se implementó paulatinamente hasta que en 1920 llegó a ser el sistema de enseñanza dominante en las facultades de derecho en Estados Unidos $^{13}$.

Sin embargo, el método del caso ha sido considerado como una variante del $\mathrm{ABP}$ porque comparte los principios y rasgos básicos del modelo de $\mathrm{ABP}$. La característica distintiva del método del caso es que plantea una situaciónproblema que se expone al alumno para que éste desarrolle propuestas

11 Frida Díaz Barriga, Enseñanza situada: vínculo entre la escuela y la vida (México: McGraw Hill, 2005).

12 Carlos Sola Ayape, Aprendizaje Basado en Problemas, de la teoría a la práctica (México: Trillas, 2005).

13 José Manuel Cortés Martín, "El aprendizaje basado en problemas como técnica didáctica del derecho internacional público”, Docencia y Derecho, n. 2 (2010): 1-15. 
REVISTA PEDAGOGÍA UNIVERSITARIA Y DIDÁCTICA DEL DERECHO [ISSN 0719-5885]

Unidad de Pedagogía Universitaria y Didáctica del Derecho, Universidad de Chile

$\mathrm{N}^{\circ}$ 1, vol. 4, $1^{\circ}$ semestre de 2017, 189-224 pp.

conducentes a su análisis o solución, pero se ofrece en un formato de narrativa o historia que contiene una serie de atributos que muestran su complejidad y multidimensionalidad. Los casos pueden tomarse de la "vida real" o bien consistir en casos simulados. Un ejemplo de aplicación del método del caso a la enseñanza del derecho mercantil lo podemos apreciar en el trabajo de Vargas Vasserot ${ }^{14}$, de quien retomamos algunos elementos para evaluar nuestra experiencia.

\section{J ustificaciones para implementar el ABP}

En la vasta literatura sobre el $\mathrm{ABP}$ se reportan sus virtudes y debilidades ${ }^{15}$. La mayoría se centra en su comparativo con las clases tradicionales. Entre sus bondades se destacan el incremento de conocimiento del estudiante sobre la materia, la habilidad para resolver problemas reales, la motivación para aprender ${ }^{16}$, el uso de estrategias para obtener información ${ }^{17}$, la capacidad crítica para analizar información ${ }^{18}$; promueve el trabajo en equipo, el

14 Carlos Vargas Vasserot, "El método del caso en la enseñanza del Derecho: experiencia piloto de un piloto novel", Revista de Formación e Innovación Educativa Universitaria 2, n. ${ }^{\circ} 4$ (2009): 193-206.

${ }^{15}$ Peter Orji, "Problem-based approach in property law - A university's strategy in focus”. Law Teacher 49, n. ${ }^{\circ} 3$ (2015):372-387.

${ }^{16}$ Mathieu Nendaz y Ara Tekian, "Assessment in problem-based learning medical schools: a literature review”, Teaching and Learning in Medicine 11, n. 4 (1999): 232-243

${ }^{17}$ William Stepien \& Shelagh Gallagher, "Problem-based learning: As authentic as it gets", Educational Leadership 50, n. ${ }^{\circ} 7$ (1993) 25-28

${ }^{18}$ J osé Antonio Molina Ortíz et al., "Aprendizaje basado en problemas: una alternativa al método tradicional”, Revista de la Red Estatal de Docencia Universitaria 3, n. ${ }^{\circ} 2$ (2003): 7985 
REVISTA PEDAGOGÍA UNIVERSITARIA Y DIDÁCTICA DEL DERECHO [ISSN 0719-5885]

Unidad de Pedagogía Universitaria y Didáctica del Derecho, Universidad de Chile

$\mathrm{N}^{\circ}$ 1, vol. 4, $1^{\circ}$ semestre de 2017, 189-224 pp.

pensamiento crítico, la compresión ${ }^{19}$ y el desarrollo de las capacidades metacognitivas ${ }^{20}$.

Por otro lado, Bridges, justifica el uso del ABP sobre tres ejes: las razones cognitivas, motivaciones y funcionales. En cuanto a las razones cognitivas, Bridges señala que dado que con las clases tradicionales los estudiantes retienen muy poco de lo que aprenden y no utilizan adecuadamente los conocimientos aprendidos, los instructores deben crear mecanismos para recordar lo aprendido y usar apropiadamente los conocimientos en la futura práctica profesional. Es precisamente en esta tesitura que el ABP crea las tres condiciones (a. activación de los conocimientos previos, b. similitud de los contextos donde se aprende la información y donde ésta se aplica posteriormente, y c. oportunidad de elaborar la información aprendida durante el proceso de solución de los problemas) que la teoría de la información relaciona con la retroalimentación subsecuente y el uso apropiado de nueva información. La elaboración de información se presenta en forma de discusión, intercambio de puntos de vista y preparación de informes y ponencias sobre lo aprendido durante el proceso de solución del problema $^{21}$.

Por otro lado, en cuanto a las justificaciones motivaciones Bridges, expone que de acuerdo a la teoría de la motivación la gente está dispuesta a emprender una tarea de en la medida en que sea capaz de realizarla con éxito

${ }^{19}$ Harold B. III White, "Dan Tries Problem-Based Learning: A Case Study", To Improve the Academy 370 (1996): 75- 91.

20 Theresa Kwong Downing et al., "Problem-based learning and the development of metacognition", Higher Education 57, n. ${ }^{\circ} 5$ (2009): 609-621

${ }^{21}$ Edwin Bridges, Problem Based Learning for Administrators. 2da ed., (United States of America: University of Oregon, 1993), 164. 
REVISTA PEDAGOGÍA UNIVERSITARIA Y DIDÁCTICA DEL DERECHO [ISSN 0719-5885]

Unidad de Pedagogía Universitaria y Didáctica del Derecho, Universidad de Chile

$\mathrm{N}^{\circ}$ 1, vol. 4, $1^{\circ}$ semestre de 2017, 189-224 pp.

y la recompensa esperada si la desarrolla pertinentemente. En esta línea, el ABP tiene seis puntos que lo hacen intrínsecamente gratificante para la mayoría de los estudiantes:

a. proporciona oportunidades para desempeñar roles activos,

b. incluye objetivos ambiciosos e interrogantes divergentes,

c. incluye simulaciones,

d. promueve la retroalimentación inmediata,

e. proporciona oportunidades para elaborar productos terminados, y

f. proporciona una oportunidad para interactuar con colegas 22 .

Con respeto a la justificación funcional, Bridges basa su análisis en cuatro dimensiones: a. ritmo de trabajo, b. la jerarquía del trabajo, c. el carácter de las comunicaciones y d. el rol de las emociones en el trabajo. En cuanto al ritmo de trabajo, Bridges argumenta que el $\mathrm{ABP}$ reduce la brecha entre el trabajo de un estudiante y el trabajo profesional. Así, por ejemplo, en un ambiente de $\mathrm{ABP}$ los estudiantes trabajan en concordancia con fechas límites, por lo que ven la necesidad de equilibrar los tiempos de entendimiento y actuación. Respecto a la jerarquía del trabajo, los estudiantes adoptan el papel de líderes y facilitadores. Con estas experiencias llegan a apreciar la importancia de las funciones de gestión, de la delegación de responsabilidades y de las dificultades inherentes cuando se trata de obtener resultados a través de otras personas. En relación al carácter de las comunicaciones en ambientes del ABP, esta es escrita, al igual que la enseñanza tradicional, pero primordialmente oral. Esto crea una comunicación de dos vías y relega la comunicación unidireccional. Finalmente, en ambientes del ABP los estudiantes experimentan los problemas emocionales al trabajar con personas. De esta forma se crean

22 Bridges, Problem Based learning, 164. 
REVISTA PEDAGOGÍA UNIVERSITARIA Y DIDÁCTICA DEL DERECHO [ISSN 0719-5885]

Unidad de Pedagogía Universitaria y Didáctica del Derecho, Universidad de Chile

$\mathrm{N}^{\circ}$ 1, vol. 4, $1^{\circ}$ semestre de 2017, 189-224 pp.

oportunidades para que los estudiantes desarrollen su competencia de interpretar y responder a las emociones y sentimientos de los demás, sobre todo si el proyecto no se termina exitosamente pues tendrán experiencias sobre cómo enfrentar la frustración, ira y decepción grupal ${ }^{23}$.

\section{Aplicación del ABP a la asignatura de Derecho Procesal Civil}

En la Universidad del Istmo, la materia de DPC, la cual se imparte en el quinto semestre de la licenciatura en Derecho, tiene como objetivos: 1) Conocer, analizar, explicar y dominar los aspectos teóricos y prácticos del DPC, a fin de interpretar y aplicar correctamente el CPCEO a casos concretos en la práctica profesional; y 2) Conocer, analizar, explicar y dominar los aspectos teóricos y prácticos del DPC que posibiliten la adecuada interpretación y aplicación supletoria del CFPC a casos concretos en la práctica profesional.

Cabe señalar que en la asignatura previa de teoría general del proceso se obtienen los aspectos teóricos del proceso civil, además se tiene contacto, aunque sea de forma general, con códigos procesales, por lo que los alumnos adquieren un conocimiento de leyes adjetivas. Lo anterior permite iniciar directamente con los aspectos prácticos en el quinto semestre y materializar las diferentes etapas del proceso jurisdiccional en la vía ordinaria o especial ${ }^{24}$ según la controversia en materia civil que sea asignada.

${ }^{23}$ Ibíd, 164. .

${ }^{24}$ La vía es propiamente el tipo de juicio elegido por el actor para entablar su demanda. J osé Ovalle Favela, Derecho procesal civil. 10ª̣ ed. (México: Oxford, 2013), 95. 
REVISTA PEDAGOGÍA UNIVERSITARIA Y DIDÁCTICA DEL DERECHO [ISSN 0719-5885]

Unidad de Pedagogía Universitaria y Didáctica del Derecho, Universidad de Chile

$\mathrm{N}^{\circ}$ 1, vol. 4, $1^{\circ}$ semestre de 2017, 189-224 pp.

Por lo anterior, podemos ceñir el objetivo de la asignatura de DPC al dominio de los aspectos prácticos en el que se involucran la interpretación y aplicación del CPCEO a una controversia. Es por ello que la metodología del ABP ha sido considerada la más pertinente, pues su diseño permite tener la oportunidad de plantear un problema, el cual se presenta en forma de una demanda, y posteriormente, agotados los procedimientos necesarios, el alumno construye una sentencia, la cual es una propuesta de solución a dicho problema.

Cabe señalar que el segundo objetivo del programa de estudio de la asignatura de DPC se logró a la par del primero, pues la supletoriedad del CFPC se expresa en disposiciones específicas del CPCEO, y en la medida en que se agota cada etapa procesal, se va aplicando dicho código y materializando la complementación de leyes ${ }^{25}$.

\section{Planificación del curso}

En el primer día de clases además de presentarles a los alumnos el programa de estudio y los temas clave del mismo que se verían inmersos en el desarrollo del proceso judicial para llegar a la sentencia definitiva; se les explicó la forma de trabajo en la que se implementa la metodología del ABP. De esta manera se abordaron nueve de las doce unidades consideradas en el

25 Quisiéramos indicar que, si bien es cierto que hay artículos expresos de previsión de supletoriedad, también lo es, que no hay regulación expresa que establezca que para todo lo no previsto en el CPCEO se aplique el CFPC, por lo que cabe la duda razonable de sí la supletoriedad es en general. 
REVISTA PEDAGOGÍA UNIVERSITARIA Y DIDÁCTICA DEL DERECHO [ISSN 0719-5885]

Unidad de Pedagogía Universitaria y Didáctica del Derecho, Universidad de Chile

$\mathrm{N}^{\circ}$ 1, vol. 4, $1^{\circ}$ semestre de 2017, 189-224 pp.

programa de estudios de la materia. Así mismo se les explicó la forma de evaluación.

Los alumnos trabajaron en parejas y cada uno de ellos elaboró una demanda, la cual se intercambió con su compañero. De esta forma ambos alumnos experimentaron el proceso como parte actora y como parte demandada. La intervención del tercer sujeto en la relación jurídica procesal, el juez, la realizó alguno de los integrantes del mismo equipo, solo que en cada momento procesal se le designó para guardar un equilibrio en las cargas de trabajo. Así mismo, se hizo énfasis en algunas reglas generales en cuanto a la forma, estructura y contenido para la presentación de los documentos a construir. La forma en cómo se hizo la distribución de las intervenciones se muestra en el Cuadro 1.

Cuadro 1. Distribución de los escritos realizados.

\begin{tabular}{|c|c|c|}
\hline $\begin{array}{l}\text { Documentos de acuerdo a las } \\
\text { etapas procesales }\end{array}$ & $\begin{array}{l}\text { Quién lo elabora } \\
\text { en la práctica } \\
\text { profesional }\end{array}$ & $\begin{array}{lll}\text { Quién } & & \text { lo } \\
\text { elaboró en } & \text { el } \\
\text { curso } & & \end{array}$ \\
\hline 1. Demanda con anexos & $\begin{array}{l}\text { Abogado de la parte } \\
\text { actora }\end{array}$ & Alumno A \\
\hline 2. Auto admisorio & Juez & Alumno A \\
\hline 3. Cédula de notificación & Juez & Alumno A \\
\hline 4. Razón del actuario & Actuario del juzgado & Alumno A \\
\hline 5. Contestación de la demanda & $\begin{array}{l}\text { Abogado de la parte } \\
\text { demandada }\end{array}$ & Alumno B \\
\hline 6. Auto que recae & Juez & Alumno B \\
\hline
\end{tabular}


REVISTA PEDAGOGÍA UNIVERSITARIA Y DIDÁCTICA DEL DERECHO [ISSN 0719-5885]

Unidad de Pedagogía Universitaria y Didáctica del Derecho, Universidad de Chile

$\mathrm{N}^{\circ}$ 1, vol. 4, $1^{\circ}$ semestre de 2017, 189-224 pp.

contestación de la demanda

7. Desahogo de la vista de Abogado de la parte Alumno A excepciones actora
8. Auto que recae al desahogo de Juez
Alumno B

la vista y que ordena abrir el periodo

de ofrecimiento de pruebas

9. Ofrecimiento de pruebas Abogados de ambas Alumnos Ay B partes

10. Auto que admite y ordena la Juez

Alumno B

preparación de pruebas

11. Acta de audiencia de desahogo J uez ${ }^{26}$ Alumno B de pruebas

12. Escrito de solicitud de fecha Abogado de la parte Alumno A para audiencia y término para dictar actora o de la parte sentencia demandada

13. Acuerdo que recae a la Juez Alumno B solicitud anterior

\begin{tabular}{lll}
\hline 14. Escrito de Alegatos & $\begin{array}{l}\text { Abogado de la parte } \\
\text { actora y de la parte } \\
\text { demandada }\end{array}$ & \\
\hline 15. Sentencia & J uez & Alumnos A B A \\
\hline
\end{tabular}

Los procedimientos ordinario y sumario, regulados por el CPCEO, fueron los que se utilizaron para darle trámite legal a los diferentes tipos de acciones (derechos) ante la autoridad jurisdiccional. Finalmente se estableció la

${ }^{26}$ La duración de los cursos ha permitido realizar hasta cuatro simulacros de audiencia. 
REVISTA PEDAGOGÍA UNIVERSITARIA Y DIDÁCTICA DEL DERECHO [ISSN 0719-5885]

Unidad de Pedagogía Universitaria y Didáctica del Derecho, Universidad de Chile

$\mathrm{N}^{\circ}$ 1, vol. 4, $1^{\circ}$ semestre de 2017, 189-224 pp.

calendarización de entrega de documentos para que coincidieran en la medida de lo posible con las fechas de los tres exámenes parciales y el examen ordinario para efectos de asentar las calificaciones correspondientes.

\section{Ejecución y seguimiento}

En el primer día de clases se presentó a los alumnos el programa de estudio, los objetivos, y acciones a seguir. Además, se les explicó la metodología a utilizar, los avances a presentar, los productos a construir en cada etapa y su forma de evaluación. Por lo que hace a la explicación de la técnica del $\mathrm{ABP}$, se señaló la manera en que se ejecutaría cada paso en el desarrollo de las unidades del programa de estudio, con algunas modificaciones de la metodología debido a las características de la asignatura jurídica que se abordó.

Tomando como guía la propuesta de Carlos Sola Ayape, el primer paso del $\mathrm{ABP}$, que consiste en la presentación y lectura comprensiva del escenario, se implementó de la siguiente manera. Se formaron parejas de alumnos y cada equipo desarrolló dos litigios ${ }^{27}$. Ambos estudiantes elaboraron una demanda en contra de su respectivo compañero y crearon un escenario diferente, es decir, una historia que contenía un conflicto jurídico en materia civil, el cual fue resuelto a través de un procedimiento regulado por el CPCEO.

27 Conflicto jurídicamente trascendente, que constituya el punto de partida o causa determinante de un proceso, de una autocomposición o de una autodefensa, según Niceto Alcalá-Zamora y Castillo, en Cipriano Gómez Lara, Teoría general del proceso, $10^{\underline{a}}$ ed. (México: Oxford, 2004), 2. 
Para la construcción del escrito de demanda, el alumno recibió una acción, es decir, se le indicó el derecho que alegaría ante el juez. Con base en ello definió los elementos que necesitó para encuadrar ese derecho, los hechos que tuvo que articular y los documentos a elaborar (actas de nacimiento, títulos de propiedad, contratos, entre otros). De forma simultánea en clase se analizaron los contenidos correspondientes, como los requisitos de la demanda, la estructura de la demanda, la autoridad competente (por criterio de territorio, materia, grado, cuantía), sujetos del proceso, representación, entre otros. Cabe mencionar que desde la elaboración de los primeros documentos los alumnos manifestaron dudas, las cuales fueron resueltas en clase o fuera de ellas, por lo que el $\mathrm{ABP}$ requiere de más tiempo que una técnica memorística.

Posteriormente, se elaboraron los escritos que son dictados por un juez y por el notificador adscrito al juzgado. Con estos documentos en una carpeta, como los expedientes reales de un juzgado, se realizó un intercambio de los mismos. En este momento es cuando se abordó el segundo paso del ABP, la definición del problema, en la que cada estudiante identifica en qué consisten los argumentos con base en los cuales se le está demandando, es decir, determina el derecho que está haciendo valer la parte que promueve el juicio en su contra, pero no solo enmarcado en los hechos relatados, sino también en la regulación de esos hechos jurídicos por el Código Civil para el Estado de Oaxaca (CCEO), lo que en nuestra disciplina llamamos motivación y fundamentación de un derecho. De esta etapa dependió la definición del reto al que se enfrentó el alumno que fungió como parte demandada, pues en este momento comenzó a visualizar la posibilidad de una defensa. Los temas reflexionados en el aula fueron aquellos relacionados con la forma de contestar una demanda, excepciones y defensas, su motivación, fundamentación y prueba de las mismas. 
Por lo que respecta al tercer paso, lluvia de ideas, de la metodología del $\mathrm{ABP}$, esta se desarrolló cuando los alumnos en su rol de demandados analizaron la problemática jurídica que se les planteó y reflexionaron sobre las diversas posibilidades que tuvieron para contestar la demanda. En dicho estudio los alumnos identificaron qué conocimientos jurídicos poseen y de cuáles carecen. De forma particular, los estudiantes revisaron figuras jurídicas involucradas y reguladas por el CCEO, buscaron definiciones e interpretaron normas jurídicas relacionadas.

Con base en el conocimiento de materias previas y de los contenidos correspondientes de DPC, los estudiantes eligieron una opción de defensa y con esta construyeron los hechos necesarios, alegaron sus fundamentos jurídicos y ofrecieron pruebas. Cabe señalar que esta fue la segunda vez que el alumno tuvo que elaborar una estrategia de prueba, pues al hacer su demanda, en su rol de parte actora, también creó una táctica probatoria. En esta etapa se involucra el cuarto paso del ABP, clasificación de las ideas, pues al identificar cada elemento que debe ser probado, se ordenan los hechos a acreditar y las pruebas idóneas para hacerlo.

En su estrategia de defensa, el alumno determinó sus objetivos a probar. Para lograrlos consideró los documentos pertinentes para avalar su dicho, las pruebas específicas (dictamen pericial, testigos, fotografías, entre otros) y la regulación de las mismas de acuerdo al CPCEO en cuanto a requisitos de ofrecimiento, forma de preparación y procedimiento de desahogo. Con lo anterior se materializaron los objetivos de aprendizaje, los cuales corresponden al quinto paso del ABP.

Para este momento del curso ambos integrantes del equipo habían leído, aclarado palabras, identificado y definido elementos clave, seleccionado ideas 
REVISTA PEDAGOGÍA UNIVERSITARIA Y DIDÁCTICA DEL DERECHO [ISSN 0719-5885]

Unidad de Pedagogía Universitaria y Didáctica del Derecho, Universidad de Chile

$\mathrm{N}^{\circ}$ 1, vol. 4, $1^{\circ}$ semestre de 2017, 189-224 pp.

principales y secundarias para continuar con el proceso y visualizarlo desde tres perspectivas: como actor, como demandado, y como autoridad jurisdiccional. Éste último rol debido a que en ocasiones algún integrante de cada pareja se desempeñó como juez.

Además, en clase se revisaron todos los temas que marca el programa, que dicho sea de paso, el tema de pruebas es el más amplio porque la revisión de regulación de cada prueba fue exhaustiva y, a la par, el alumno seleccionó las pruebas que utilizaría de acuerdo al catálogo que ofrece el CPCEO.

El sexto paso del $A B P$, el cual se refiere a la etapa de investigación, se realizó integrando lo que conocemos como fuentes formales del derecho, ${ }^{28}$ es decir, con la consulta de leyes, jurisprudencia, principios generales del derecho, entre otras. El manejar estas fuentes de manera adecuada le permite al estudiante tener posibilidades de estructurar una interpretación de las normas jurídicas, para obtener una sentencia favorable a sus intereses.

Las oportunidades procesales son las mismas para los dos estudiantes en ambas controversias. Para continuar con el proceso ante el juez, tanto la parte actora como demandada realizaron un escrito de alegatos en los que exponen los motivos, razones y argumentaciones por las que consideran que sus hechos alegados fueron probados y que las normas interpretadas favorecieron la postura que sostuvieron.

En cada etapa procesal el resultado fue un documento, pues aún las controversias en materia civil siguen el principio de derecho escrito. Así, el

${ }^{28}$ La palabra fuente tiene tres acepciones, una de ellas son las fuentes formales por la cual se entiende que son los procesos de creación de las normas jurídicas. Eduardo García Máynez, Introducción al estudio del derecho, 65쯔 ed. (México: Porrúa, 2013, 53. 
REVISTA PEDAGOGÍA UNIVERSITARIA Y DIDÁCTICA DEL DERECHO [ISSN 0719-5885]

Unidad de Pedagogía Universitaria y Didáctica del Derecho, Universidad de Chile

$\mathrm{N}^{\circ}$ 1, vol. 4, $1^{\circ}$ semestre de 2017, 189-224 pp.

seguimiento del proceso se hizo a través de un documento dirigido a la autoridad jurisdiccional competente, atendiendo a requisitos de forma, de fondo, motivado y fundado.

Por último, el séptimo paso del $\mathrm{ABP}$, presentación y discusión de los resultados, se materializó con una sentencia. Aunque cabe indicar que en cada etapa procesal el alumno practicó una y otra vez todas las etapas del ABP, pues en cada momento procesal tuvo que comprender un escenario, definir el problema, considerar diversas alternativas, clasificar sus ideas, optar por una resolución como parte o como juzgador, según correspondiera, fijar objetivos, investigar y elaborar documentos (ver Cuadro 1).

\section{Evaluación de solución}

Cómo se señaló anteriormente, con el avance del proceso se entregaron diversos documentos que fueron evaluados. Entre los rubros tomados en cuenta para asentar una calificación se encuentran los siguientes:

- Respecto de la estructura, se revisó que el rubro del documento estuviera bien escrito, se dirigiera a la autoridad competente, que la parte de la comparecencia fuera clara, que se indicaran las razones de lo solicitado y los artículos en los que se fundamentaba su solicitud, que fuera firmado, que no tuviera errores ortográficos o mecanográficos y que existiera congruencia, claridad y precisión en los escritos elaborados.

En lo referente a los elementos de fondo, se valoró la argumentación que se ofreció, la idoneidad de los argumentos, la estrategia de alegación del derecho cuando se es actor y de defensa cuando se es demandado. 
REVISTA PEDAGOGÍA UNIVERSITARIA Y DIDÁCTICA DEL DERECHO [ISSN 0719-5885]

Unidad de Pedagogía Universitaria y Didáctica del Derecho, Universidad de Chile

$\mathrm{N}^{\circ}$ 1, vol. 4, $1^{\circ}$ semestre de 2017, 189-224 pp.

Como se señaló al principio, en cada examen parcial se promedió el avance de las actuaciones en el expediente, teniendo mayor peso en la calificación final la evaluación continua que el examen que se aplicó el día programado. En el examen se le pidió al estudiante que elaborará alguno de los escritos con base en datos específicos o una situación con información concreta.

\section{Evaluación del ABP por los alumnos}

Para conocer la opinión de los estudiantes sobre la aplicación de la metodología del ABP a la materia de DPC, se aplicó una encuesta tomando como base los ítems que usó Carlos Vargas Vasserot para evaluar el método del caso implementado en el curso 2007/2008 de derecho mercantil de la licenciatura en derecho en la universidad de Almería ${ }^{29}$.

$\mathrm{Al}$ instrumento se le realizaron algunas modificaciones en la redacción de los ítems acorde a la materia de DPC y se direccionaron las preguntas en seis dimensiones o criterios. El resultado fue un instrumento con 19 ítems, de los cuales los dos primeros midieron lo estimulante que les resultó el método. Las preguntas tres, cuatro y cinco evaluaron el trabajo que desarrollaron en equipo. La pregunta seis reportó su disposición para trabajar fuera de clase. La siete su opinión sobre haber abordado sólo un caso en todas sus etapas. Las preguntas ocho, nueve, 10, 11 y 12 permitieron conocer su percepción sobre las habilidades adquiridas; la 13, 14, 15 y 16 mostraron su apreciación sobre su formación, y la 17,18 y 19 determinaron la valoración global del método (Cuadro 2).

\footnotetext{
29 Vargas Vasserot, "El método del caso en la enseñanza del Derecho".
} 
REVISTA PEDAGOGÍA UNIVERSITARIA Y DIDÁCTICA DEL DERECHO [ISSN 0719-5885]

Unidad de Pedagogía Universitaria y Didáctica del Derecho, Universidad de Chile

$\mathrm{N}^{\circ}$ 1, vol. 4, $1^{\circ}$ semestre de 2017, 189-224 pp.

Cuadro 2. Ítems del cuestionario de acuerdo a las características evaluadas.

\begin{tabular}{|c|c|}
\hline Criterio & Ítems \\
\hline $\begin{array}{l}\text { Lo estimulante } \\
\text { que les resultó } \\
\text { el ABP }\end{array}$ & $\begin{array}{l}\text { 1. La metodología del ABP me motivó más para estudiar } \\
\text { 2. Esta manera de trabajar (aprendizaje cooperativo) aumentó } \\
\text { mi interés por los contenidos de la asignatura }\end{array}$ \\
\hline $\begin{array}{lr}\text { Evaluación } & \text { del } \\
\text { trabajo } & \text { en } \\
\text { equipo } & \end{array}$ & $\begin{array}{l}\text { 3. Me gustó trabajar en equipo } \\
\text { 4. Aprendí más resolviendo los casos con mi compañero de } \\
\text { equipo } \\
\text { 5. Resolvimos los conflictos internos dentro del grupo }\end{array}$ \\
\hline $\begin{array}{l}\text { Disposición } \\
\text { para trabajar } \\
\text { fuera de clase }\end{array}$ & $\begin{array}{l}\text { 6. Estuve dispuesto a trabajar fuera de clase en la resolución de } \\
\text { los casos }\end{array}$ \\
\hline $\begin{array}{l}\text { Opinión por } \\
\text { abordar un solo } \\
\text { caso }\end{array}$ & 7. Me gustó trabajar un caso en todas sus etapas \\
\hline $\begin{array}{l}\text { Percepción } \\
\text { sobre } \\
\text { habilidades } \\
\text { adquiridas }\end{array}$ & $\begin{array}{l}\text { 8. El sistema de contestación a la demanda ha sido de utilidad } \\
\text { en mí proceso de formación } \\
\text { 9. La exposición en la audiencia de desahogo de pruebas me } \\
\text { sirvió para mejorar mi expresión oral y para hablar en público } \\
\text { 10. Con el ABP ha mejorado mi expresión escrita } \\
\text { 11. Con este curso han mejorado mis conocimientos de } \\
\text { informática y de herramientas asociadas (DOC, PPT, Internet) } \\
\text { 12. Ha mejorado mi habilidad para el uso de bases de datos de } \\
\text { legislación yjurisprudencia }\end{array}$ \\
\hline $\begin{array}{l}\text { Apreciación } \\
\text { sobre su }\end{array}$ & $\begin{array}{l}\text { 13. Un buen número de alumnos adquirió un nivel suficiente } \\
\text { para aprobar con esta metodología }\end{array}$ \\
\hline
\end{tabular}


REVISTA PEDAGOGÍA UNIVERSITARIA Y DIDÁCTICA DEL DERECHO [ISSN 0719-5885]

Unidad de Pedagogía Universitaria y Didáctica del Derecho, Universidad de Chile

$\mathrm{N}^{\circ}$ 1, vol. 4, $1^{\circ}$ semestre de 2017, 189-224 pp.

\begin{tabular}{l|l}
\hline formación & $\begin{array}{l}\text { 14. He aprendido más con esta metodología que con el método } \\
\text { tradicional } \\
\text { 15. Con esta metodología me siento mejor preparado para el } \\
\text { mundo laboral que con la metodología tradicional } \\
\text { 16. Creo que estoy preparado para abordar casos reales de } \\
\text { Derecho Procesal Civil relativamente complicados }\end{array}$ \\
\hline Valoración \\
global \\
método del
\end{tabular} \mid \begin{tabular}{l}
$\begin{array}{l}\text { 17. Me gustaría repetir la experiencia en otras asignaturas } \\
\text { 18. Estoy contento con la experiencia del método del ABP } \\
\text { realizado en este curso } \\
\text { 19. Mi valoración global del método del ABP para la enseñanza } \\
\text { del Derecho es favorable }\end{array}$ \\
\hline
\end{tabular}

Fuente: Elaboración propia con base en Carlos Vargas Vasserot.

La escala de valoración empleada fue de cero a diez ( 0 a 10), en la que el cero representa la valoración mínima y el 10 la máxima. Los alumnos interpretan fácilmente esta escala pues es la misma que se usa en la universidad, donde las calificaciones 6, 7, 8, 9 y 10 son notas aprobatorias y se les relaciona con los adjetivos: suficiente, regular, bueno, muy bueno y excelente, respectivamente. Las calificaciones menores a 6 representan una evaluación reprobatoria.

La consistencia interna del instrumento se realizó con el alfa de Cronbach ${ }^{30}$. Si los ítems se combinan aditivamente y miden la característica no observable en la misma dirección, entonces los ítems están fuertemente correlacionados y por ende se tiene un instrumento fiable. En tal caso el alfa de Cronbach tiende al valor 1. En contraste, alfa tiende a cero si los ítems son

${ }^{30}$ Lee J . Cronbach, "Coefficient alpha and the internal structure of tests", Psychometrica $16,{ }^{\circ} 3$ (1951): 297-334 
REVISTA PEDAGOGÍA UNIVERSITARIA Y DIDÁCTICA DEL DERECHO [ISSN 0719-5885]

Unidad de Pedagogía Universitaria y Didáctica del Derecho, Universidad de Chile

$\mathrm{N}^{\circ}$ 1, vol. 4, $1^{\circ}$ semestre de 2017, 189-224 pp.

independientes o están débilmente correlacionados. Esto indica que el instrumento no es confiable pues colecta información vía preguntas no relacionadas, conduciendo a conclusiones erróneas ${ }^{31}$.

Los alumnos que participaron en la encuesta fueron 38 de un total de 40, es decir, se encuestó a 95\% de los estudiantes de los tres grupos que tomaron el curso de DPC con la metodología del ABP. Los cursos fueron tomados en los periodos de octubre de 2012 a febrero de 2013, octubre de 2013 a febrero de 2014 y octubre de 2014 a febrero de 2015.

\section{Resultados de la encuesta}

En seguida se presentan los histogramas de frecuencias así como las funciones de densidad estimadas vía el método de estimación tipo núcleo ${ }^{32}$. Ambos se realizaron con el paquete estadístico $\mathrm{R}^{33}$.

${ }^{31}$ En la literatura se reporta que no hay un valor mínimo para que el alfa de Cronbach repercuta en un instrumento fiable. Sin embargo, J asón Osborne indica que la fiabilidad media en revistas de prestigio oscila alrededor de 0.83, en Jason W. Osborne, "Effect sizes and the disattenuation of correlation and regression coefficients: lessons from educational psychology”, Practical Assessment, Research \& Evaluation 8, n. ${ }^{\circ} 11$ (2003): 1-7.

32 Murray Rosenblatt, "Remarks on some nonparametric estimates of a density function". The Annals of Mathematical Statistics 27, n. ${ }^{\circ 3}$, (1956): 1832-1837.

33 The R Project for Statistical Computing. 
REVISTA PEDAGOGÍA UNIVERSITARIA Y DIDÁCTICA DEL DERECHO [ISSN 0719-5885]

Unidad de Pedagogía Universitaria y Didáctica del Derecho, Universidad de Chile

$\mathrm{N}^{\circ}$ 1, vol. 4, $1^{\circ}$ semestre de 2017, 189-224 pp.

CONFIABILIDAD DEL INSTRUMENTO

Al calcular el alfa de Cronbach con los ítems del instrumento aplicado, se obtuvo un valor de 0.91, lo que significa que el instrumento aplicado es confiable pues los ítems recopilan información consistentemente sobre la valoración de la metodología ABP.

\section{OPINIÓN SOBRE LO ESTIMULANTE DEL ABP}

En la Figura 1 se muestran los histogramas en relación a la percepción de los alumnos sobre qué tan estimulante fue la metodología del ABP: si motiva y si aumentó su interés por la asignatura de DPC. Es de notarse que en cada una de las dimensiones prevaleció la valoración en el intervalo [8, 9 y 10], es decir que la mayoría de los alumnos calificaron la estimulación al estudio entre bien, muy bien y excelente. El criterio que recibió mayor calificación fue el de el ABP les aumentó el interés por la asignatura, a esta dimensión $68.4 \%$ de los alumnos otorgó la valoración de muy bien y excelente.

Figura 1. Lo estimulante que resultó el ABP: histograma de frecuencias y densidad

estimada.
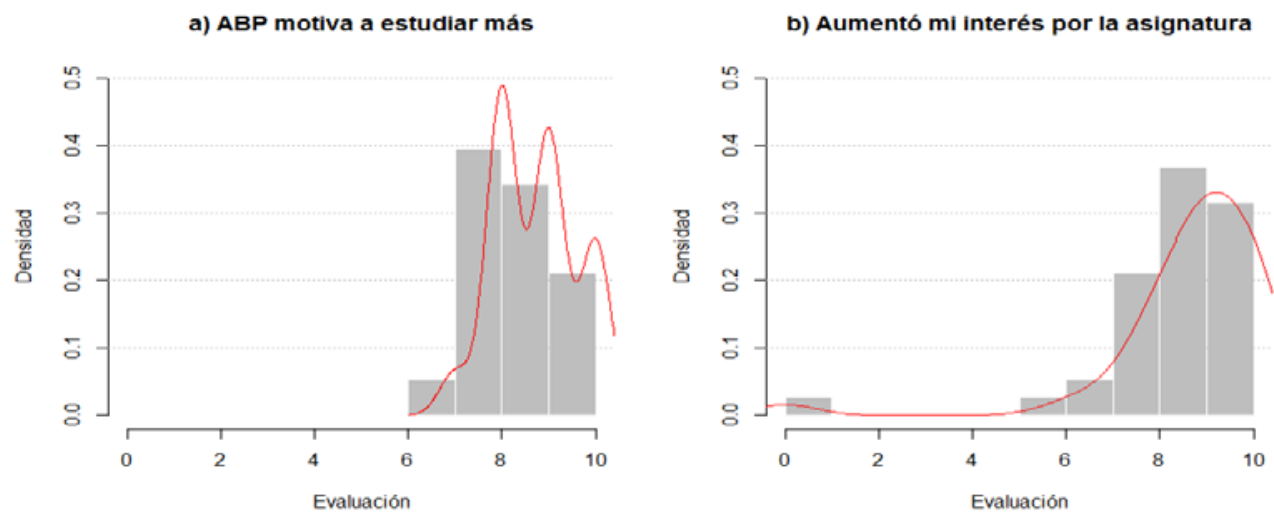
REVISTA PEDAGOGÍA UNIVERSITARIA Y DIDÁCTICA DEL DERECHO [ISSN 0719-5885]

Unidad de Pedagogía Universitaria y Didáctica del Derecho, Universidad de Chile

$\mathrm{N}^{\circ}$ 1, vol. 4, $1^{\circ}$ semestre de 2017, 189-224 pp.

Fuente: Elaboración propia con base en los resultados de la encuesta de implementación del ABP.

\section{EVALUACIÓN DEL TRABAJ O EN EQUIPO}

Por cuanto hace a la valoración sobre el trabajo en equipo, las dimensiones del gusto por esta forma de trabajo y haber aprendido más trabajando en equipo, más del 71\% de los estudiantes otorgaron una calificación entre 8 y 10, es decir, la actividades en parejas como parte actora, demandada y como juez, el intercambio de roles y el diálogo llevado a cabo fueron muy bien valorados, sobre todo para su aprendizaje (Figura 2b). La dimensión relativa a la capacidad de resolver los conflictos en el grupo muestra que hay un porcentaje mayor que asignó una calificación no aprobatoria a esta dimensión y que los demás valores asignados están distribuidos en porcentajes similares que van de 7 a 10 (Figura 2c).

Figura 2. Valoración sobre el trabajo en equipo: Histograma de frecuencias y densidad

estimada.
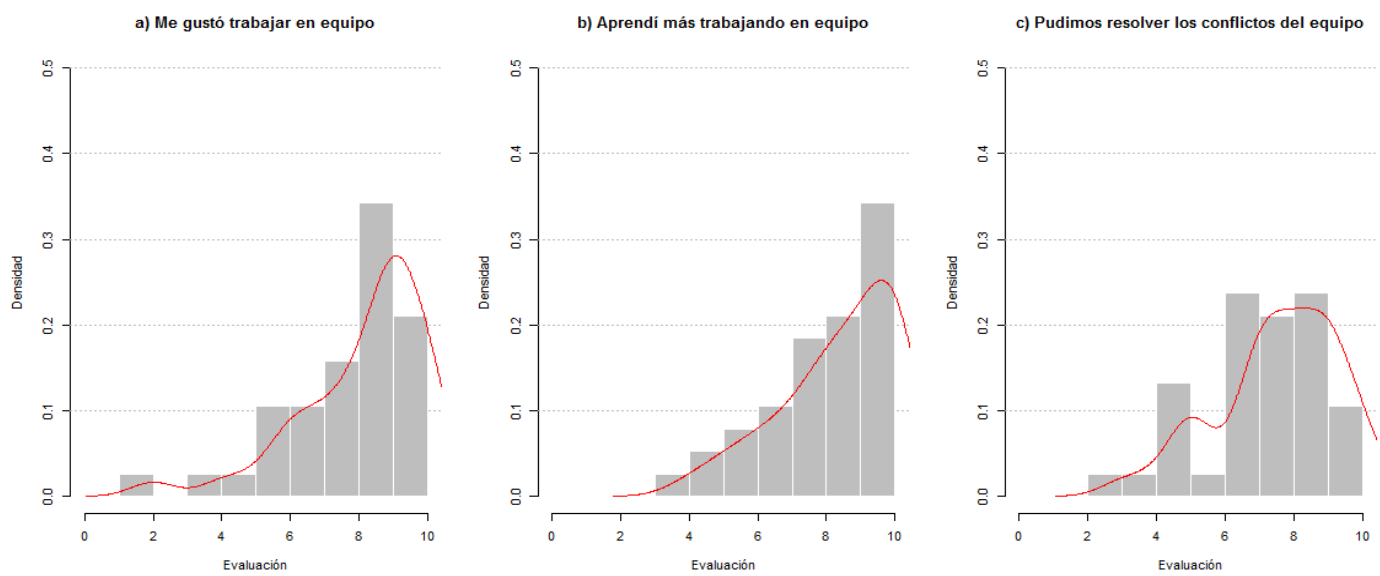

Fuente: Elaboración propia con base en los resultados de la encuesta de implementación del ABP. 
REVISTA PEDAGOGÍA UNIVERSITARIA Y DIDÁCTICA DEL DERECHO [ISSN 0719-5885]

Unidad de Pedagogía Universitaria y Didáctica del Derecho, Universidad de Chile

$\mathrm{N}^{\circ}$ 1, vol. 4, $1^{\circ}$ semestre de 2017, 189-224 pp.

DisPOSICIÓN PARA TRABAJ AR FUERA DE CLASE

En la figura 3 se muestra los histogramas mostrando dos dimensiones el trabajo fuera de clase y la aceptación de haber trabajado un caso en todas sus etapas. Respecto de la primera dimensión, aunque el trabajo fuera de clase es común para cualquier materia, en particular nosotros quisimos investigar sobre cómo fue su disposición, la cual encontramos que la mayoría de los alumnos la calificaron de buena, muy buena y excelente, siendo 73.6\% (Figura $3)$.

Figura 3. Opinión sobre el problema abordado: histograma de frecuencias y densidad estimada.

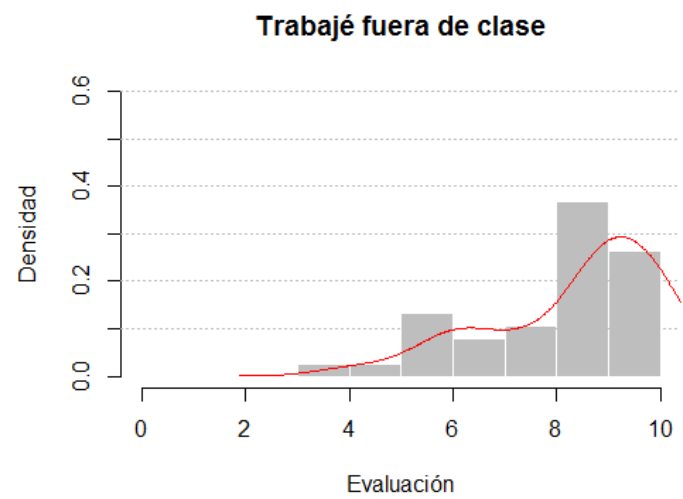

Fuente: Elaboración propia con base en los resultados de la encuesta de implementación del ABP.

\section{OPINIÓN POR ABORDAR UN SOLO CASO}

Por otro lado, es contundente el gusto de los alumnos por haber trabajado un caso con todas sus etapas, pues 52.6\% asignó un valor de excelente (Figura $4)$. 
REVISTA PEDAGOGÍA UNIVERSITARIA Y DIDÁCTICA DEL DERECHO [ISSN 0719-5885]

Unidad de Pedagogía Universitaria y Didáctica del Derecho, Universidad de Chile

$\mathrm{N}^{\circ}$ 1, vol. 4, $1^{\circ}$ semestre de 2017, 189-224 pp.

Figura 4. Opinión por abordar un solo caso: histograma de frecuencias y densidad estimada.

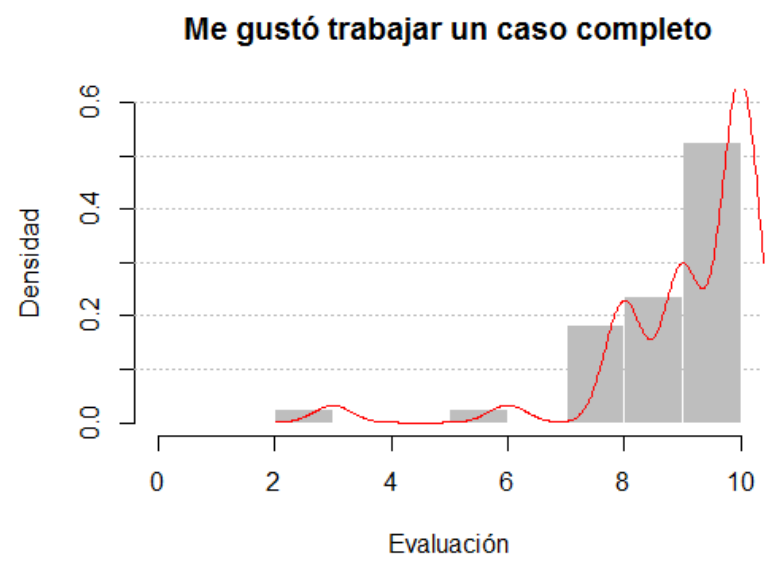

Fuente: Elaboración propia con base en los resultados de la encuesta de implementación del ABP.

\section{PERCEPCIÓN SOBRE HABILIDADES ADQUIRIDAS}

La mayoría de los alumnos opina que hay un mejoramiento de habilidades específicas a través de la metodología del ABP tal y como se aprecia en la Figura 5. Es de notarse que cada una de las dimensiones prevalece una valoración de bueno, muy bueno y excelente. La dimensión que recibió mayor calificación entre muy bien y excelente fue la de si el sistema de contestación a la demanda les ha sido útil, pues más del $84 \%$ de los alumnos otorgó esta valoración (Figura 5a). Además, cabe resaltar que ninguno de los alumnos otorgó una calificación no aprobatoria. 
REVISTA PEDAGOGÍA UNIVERSITARIA Y DIDÁCTICA DEL DERECHO [ISSN 0719-5885]

Unidad de Pedagogía Universitaria y Didáctica del Derecho, Universidad de Chile

$\mathrm{N}^{\circ}$ 1, vol. 4, $1^{\circ}$ semestre de 2017, 189-224 pp.

Figura 5. Opinión sobre habilidades específicas: histograma de frecuencias y densidad

estimada.
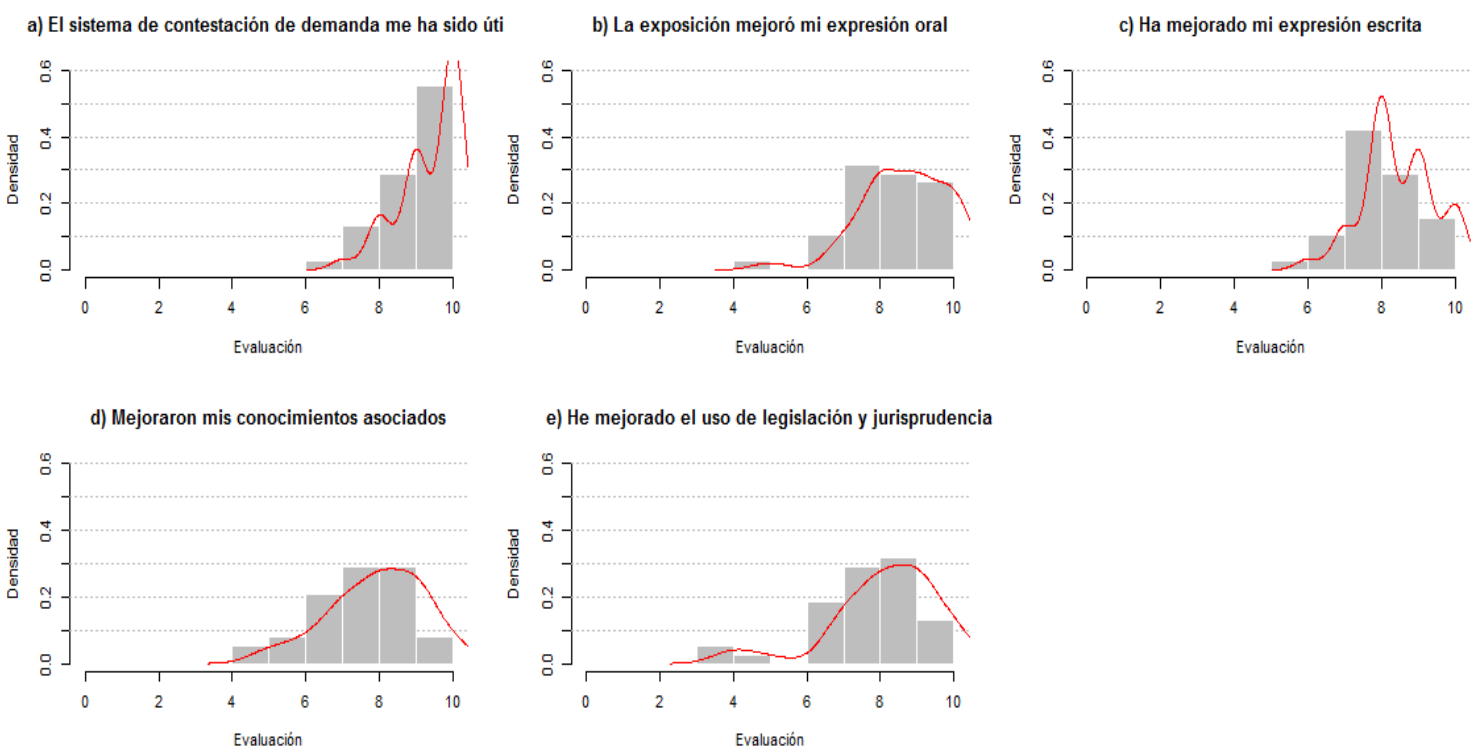

Fuente: Elaboración propia con base en los resultados de la encuesta de implementación del ABP.

Por otro lado, las dimensiones del mejoramiento de la expresión oral y escrita presentan un porcentaje del $86.8 \%$ de valoración de 8 a 10 con un mínimo de calificaciones no aprobatorias (Figuras 5b y 5c) siendo la expresión oral la que tuvo un mayor mejoramiento con la técnica de exposición en la audiencia de desahogo de pruebas, toda vez que $60.5 \%$ delos alumnos otorgó los valores de 8 y 9.

Los histogramas correspondientes al mejoramiento de conocimientos asociados, que se refiere a conocimiento sobre informática, y el mejoramiento en el uso de legislación y jurisprudencia reportan datos similares (Figuras 5d y 5e). Para estas dos dimensiones $28.9 \%$ de los estudiantes asignaron un valor de $8,28.9 \%$ y $31.6 \%$ un valor de 9 y $7.9 \%$ y $13.2 \%$ un valor de 10 . 
REVISTA PEDAGOGÍA UNIVERSITARIA Y DIDÁCTICA DEL DERECHO [ISSN 0719-5885]

Unidad de Pedagogía Universitaria y Didáctica del Derecho, Universidad de Chile

$\mathrm{N}^{\circ}$ 1, vol. 4, $1^{\circ}$ semestre de 2017, 189-224 pp.

\section{APRECIACIÓN SOBRE SU FORMACIÓN}

La Figura 6 sobre los resultados del ABP en su formación muestra que la dimensión que recibió mayor calificación entre muy bien y excelente fue en la que los alumnos consideran que aprendieron más con el método $\mathrm{ABP}$ que con el método tradicional, criterio en el que $81.6 \%$ de los alumnos otorgó esta valoración (Figura 6b). Lo cual es concordante con la dimensión sobre que con la metodología del ABP se adquiere un nivel suficiente para aprobar, pues encontramos que $81.6 \%$ asignó una calificación de 8 a 10, aunque las mayores calificaciones asignadas fueron 8 y 9 (Figura 6a).

Figura 6. Apreciación sobre el resultado en su formación: histograma de frecuencias y densidad estimada.
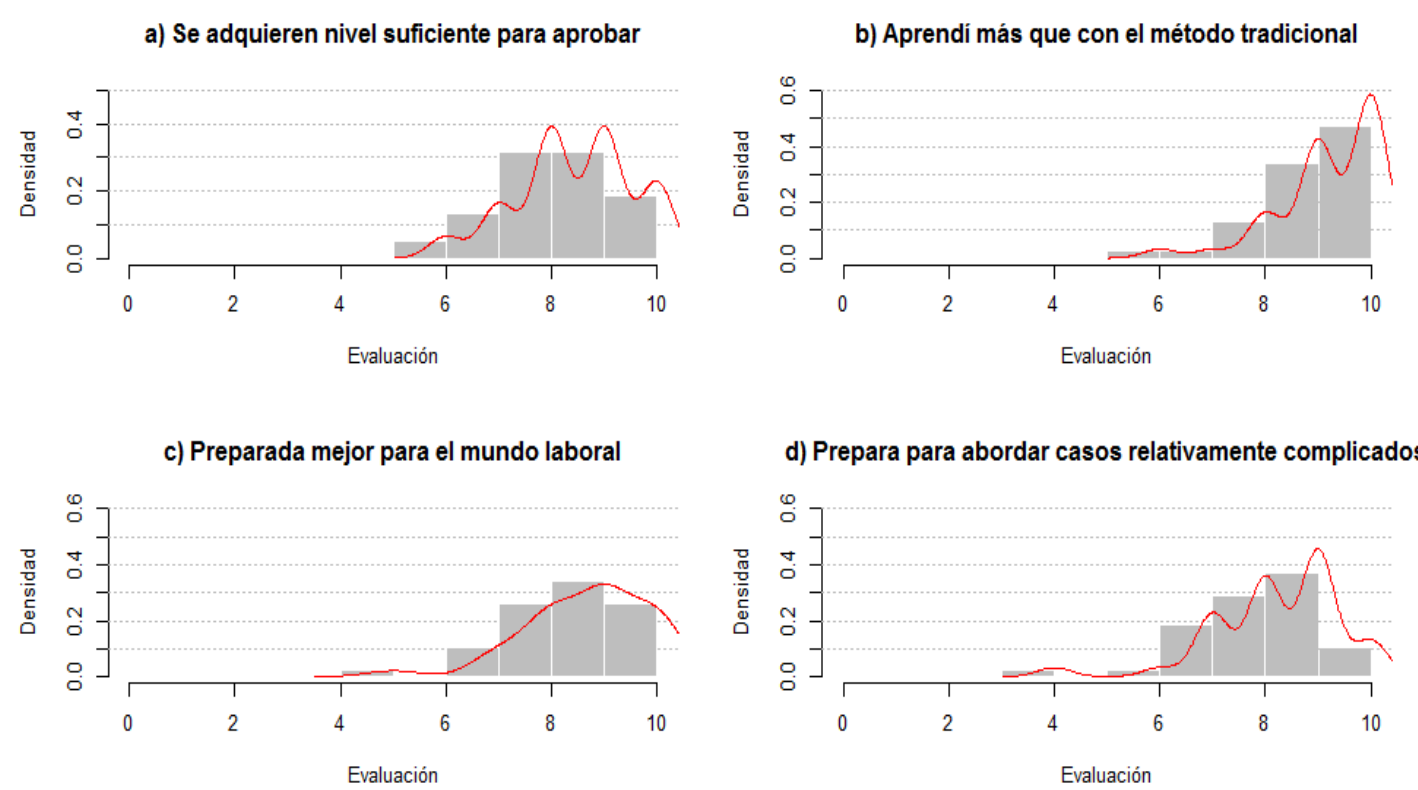

Fuente: Elaboración propia con base en los resultados de la encuesta de implementación del ABP. 
REVISTA PEDAGOGÍA UNIVERSITARIA Y DIDÁCTICA DEL DERECHO [ISSN 0719-5885]

Unidad de Pedagogía Universitaria y Didáctica del Derecho, Universidad de Chile

$\mathrm{N}^{\circ}$ 1, vol. 4, $1^{\circ}$ semestre de 2017, 189-224 pp.

Los histogramas correspondientes a las dimensiones que el ABP prepara mejor para el mundo laboral y para abordar casos relativamente complicados si bien ambos reportan un 86.8\% de valoración de 8 a 10 con un mínimo de calificaciones no aprobatorias (Figuras 6c y 6d) es de subrayar que ambos tienen una semejante asignación de los valores 8 y 9, pero una diferencia notoria en el valor 10, por lo que apreciamos que atendiendo al sentido de los ítems relacionados, los alumnos se sienten mejor preparados para el mundo laboral que con la metodología tradicional. Pero no es el mismo sentir para abordar casos reales relativamente complicados, siendo "reales" y "relativamente complicados" los adjetivos a los que atribuimos la diferencia en la asignación de valores.

\section{VALORACIÓN GLOBAL DEL MÉTODO}

Por último, en la Figura 7 sobre la evaluación general, en las tres dimensiones: me gustaría el $\mathrm{ABP}$ en otras asignaturas, contento con la experiencia del ABP y la valoración global del ABP, se aprecia que la mayoría de los alumnos otorgó una valoración entre 9 y 10, así mismo se observa que no hay una asignación de valor reprobatorio. 
REVISTA PEDAGOGÍA UNIVERSITARIA Y DIDÁCTICA DEL DERECHO [ISSN 0719-5885]

Unidad de Pedagogía Universitaria y Didáctica del Derecho, Universidad de Chile

$\mathrm{N}^{\circ}$ 1, vol. 4, $1^{\circ}$ semestre de 2017, 189-224 pp.

Figura 7. Evaluación general: histograma de frecuencias y densidad estimada.
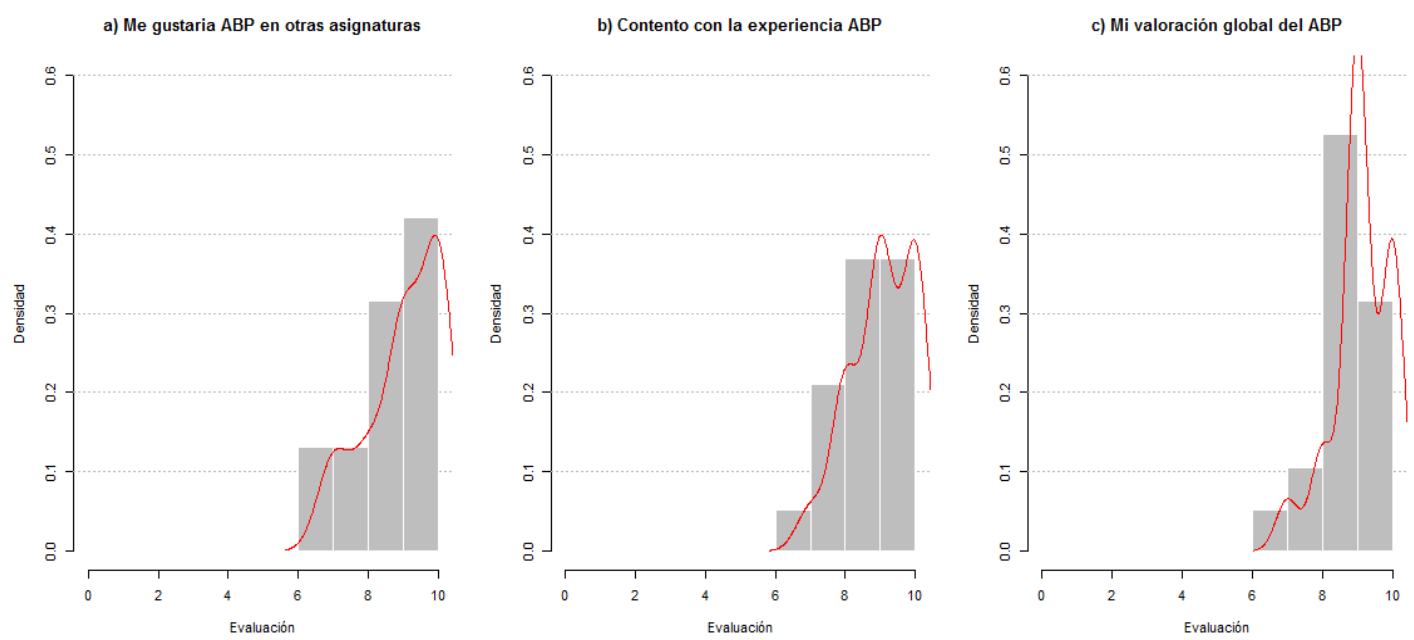

Fuente: Elaboración propia con base en los resultados de la encuesta de implementación del ABP.

Cabe resaltar que, de las tres dimensiones, la que se refiere a si les gustaría repetir la experiencia de la técnica del ABP en otras materias $42.1 \%$ de los alumnos califico como excelente, mientras que $73.6 \%$ calificó de muy buena y excelente al preguntarles si estaban contentos con la experiencia del método en el curso, siendo congruentes con la asignación del valor 9 en el criterio de valoración global del ABP como la máxima calificación por el 52.6\% de los estudiantes.

\section{Conclusiones}

La metodología del ABP permitió a los alumnos pasivos dejar de serlo y convertirse en un estudiante activo y participativo en su proceso de 
REVISTA PEDAGOGÍA UNIVERSITARIA Y DIDÁCTICA DEL DERECHO [ISSN 0719-5885]

Unidad de Pedagogía Universitaria y Didáctica del Derecho, Universidad de Chile

$\mathrm{N}^{\circ}$ 1, vol. 4, $1^{\circ}$ semestre de 2017, 189-224 pp.

aprendizaje. Partiendo de que el trabajo colaborativo es indispensable, en esta técnica se promovió la capacidad para relacionarse con sus compañeros ya fuera para desempeñar su rol como abogado de la parte actora o de la parte demandada frente a su compañero contrincante. Pero también para lograr el apoyo al llevar a cabo su audiencia, ya como juez, secretario de acuerdos, parte actora, parte demandada o testigo.

Los estudiantes encontraron en el aula la oportunidad de actuar como un abogado postulante resolviendo un problema simulado, para lo cual tuvo que hacer uso de contenidos jurídicos que ha adquirido en los anteriores semestres y que complementan la materia de DPC. Haciendo uso de su habilidad para adquirir y manejar información, integraron hechos, teorías y normas jurídicas procesales civiles para llevarlas a la práctica en cada momento procesal, y así llegar a la solución del problema planteado. En cada etapa necesitaron tomar una postura y expresarla por escrito o verbalmente, analizar e interpretar normas jurídicas, exponer razones y fundamentos; ir tejiendo una argumentación para convencer en el derecho que se defendió.

La técnica del ABP fue muy aceptada por los alumnos, en la encuesta señalaron que les ha sido muy útil en su proceso de formación, consideran que han aprendido más que con el método tradicional; que les permitió mejorar su expresión oral, su expresión escrita, la habilidad para el manejo de legislación y jurisprudencia. Cabe resaltar que, aunque señalaron que se sienten mejor preparados para el mundo laboral con el ABP, las calificaciones asignadas a su apreciación de estar preparados para abordar casos reales de DPC relativamente complicados son mínimamente menores. Creemos que esta disminución de confianza se podrá deber a que por cuestiones de tiempo solo se pudo resolver un caso en el semestre, y por encontrarse a la mitad de sus estudios de licenciatura. 
REVISTA PEDAGOGÍA UNIVERSITARIA Y DIDÁCTICA DEL DERECHO [ISSN 0719-5885]

Unidad de Pedagogía Universitaria y Didáctica del Derecho, Universidad de Chile

$\mathrm{N}^{\circ}$ 1, vol. 4, $1^{\circ}$ semestre de 2017, 189-224 pp.

Como docentes, consideramos que el resultado final de la implementación del ABP a la asignatura de DPC fue una formación significativa, práctica, organizada y motivadora.

\section{Referencias bibliográficas}

Barrows Howard. "Problem-Based learning in medicine and beyond: A brief overview". New Directions For Teaching And Learning 68 (1996): 312. http:// onlinelibrary.wiley.com/ doi/10.1002/tl.v1996:68/issuetoc

Bridges, Edwin. Problem Based Learning for Administrators. 2da ed., United States of America: University of Oregon, 1993.

Clough, Joanne \& Gillian W. Shorter. "Evaluating the effectiveness of problem-based learning as a method of engaging year one law students". Law Teacher 49, n. ${ }^{\circ} 3$ (2015):277-302. http://www.tandfonline.com.ezproxy.puc.cl/doi/full/ 10.1080/03069 $\underline{400.2015 .1011926}$

Cronbach, Lee J. "Coefficient alpha and the internal structure of tests". Psychometrica 16, n. ${ }^{\circ} 3$ (1951): 297-334.

Cortés Martín, J osé Manuel. "El aprendizaje basado en problemas como técnica didáctica del derecho internacional público". Docencia y Derecho, n. ${ }^{\circ} 2$ (2010): 1-15. 
REVISTA PEDAGOGÍA UNIVERSITARIA Y DIDÁCTICA DEL DERECHO [ISSN 0719-5885]

Unidad de Pedagogía Universitaria y Didáctica del Derecho, Universidad de Chile

$\mathrm{N}^{\circ}$ 1, vol. 4, $1^{\circ}$ semestre de 2017, 189-224 pp.

Díaz Barriga, Frida. Enseñanza situada: vínculo entre la escuela y la vida. México: McGraw Hill, 2005.

Downing, Kevin, Theresa Kwong, Sui-wah Chan, Tsz-Fung Lam, Woo-kyung Downing. "Problem-based learning and the development of metacognition". Higher Education 57, n. ${ }^{\circ}$ (2009): 609-621.

García Máynez, Eduardo. Introducción al estudio del derecho, 65a ed., México: Porrúa, 2013.

Gómez Lara, Cipriano. Teoría general del proceso, 10aㅡ ed. México: Oxford, 2004.

Hmelo-Silve, Cindy. "Problem-based learning: what and how do students learn?”. Educational Psychology Review 16, n. ${ }^{\circ 3}$ (2004): 235- 266. doi:10.1023/B:EDPR.0000034022.16470.f3

Molina Ortíz, J osé Antonio; Asunción García González, Azucena Pedraz Marcos y María Victoria Antón Nardiz. "Aprendizaje basado en problemas: una alternativa al método tradicional”. Revista de la Red Estatal de Docencia Universitaria 3, n. ${ }^{\circ} 2$ (2003): 79-85.

Morales, Patricia y Victoria Landa. "Aprendizaje Basado en Problemas". Theoria 13, n. ${ }^{\circ}$ 1(2004): 145-157.

Nendaz, Mathieu y Ara Tekian. "Assessment in problem-based learning medical schools: a literature review". Teaching and Learning in Medicine 11, n. ${ }^{\circ} 4$ (1999): 232-243. 
REVISTA PEDAGOGÍA UNIVERSITARIA Y DIDÁCTICA DEL DERECHO [ISSN 0719-5885]

Unidad de Pedagogía Universitaria y Didáctica del Derecho, Universidad de Chile

$\mathrm{N}^{\circ}$ 1, vol. 4, $1^{\circ}$ semestre de 2017, 189-224 pp.

Orji, Peter. “Problem-based approach in property law - A university's strategy in focus". Law Teacher 49, n. ${ }^{\circ 3}$ (2015):372-387. http:// www.tandfonline.com.ezproxy.puc.cl/ doi/pdf/10.1080/03069 400.2015.1040295?needAccess $=$ true

Osborne, Jason W. "Effect sizes and the disattenuation of correlation and regression coefficients: lessons from educational psychology". Practical Assessment, Research \& Evaluation 8, n. ${ }^{\circ} 11$ (2003): 1-7. http:// pareonline.net/ getvn.asp?v=8\&n=11

Ovalle Favela, J osé. Derecho procesal civil. 10ª ed., México: Oxford, 2013.

Rosenblatt, Murray. "Remarks on some nonparametric estimates of a density function". The Annals of Mathematical Statistics 27, n. ${ }^{\circ}$, (1956): 1832-1837

Rué Domingo, J oan, Antoni Font Rivas y Gisela Cebrián Bernat. “El ABP, un enfoque estratégico para la formación en educación superior. Aportaciones de un análisis de la formación en derecho". REDU: Revista de Docencia Universitaria 9, $\mathrm{n}^{\circ} 1$ (2011): 25-44. https:// polipapers.upv.es/index.php/REDU/article/view/6178/6228

Sola Ayape, Carlos. Aprendizaje Basado en Problemas, de la teoría a la práctica. México: Trillas, 2005.

Stepien, William y Shelagh Gallagher. Problem-based learning: As authentic as it gets. Educational Leadership 50, n. ${ }^{\circ} 7$ (1993) 25-28. 
REVISTA PEDAGOGÍA UNIVERSITARIA Y DIDÁCTICA DEL DERECHO [ISSN 0719-5885]

Unidad de Pedagogía Universitaria y Didáctica del Derecho, Universidad de Chile

$\mathrm{N}^{\circ}$ 1, vol. 4, $1^{\circ}$ semestre de 2017, 189-224 pp.

Vargas Vasserot, Carlos. "El método del caso en la enseñanza del Derecho: experiencia piloto de un piloto novel”. Revista de Formación e Innovación Educativa Universitaria 2, n. ${ }^{\circ} 4$ (2009): 193-206.

White, Harold B. III. "Dan Tries Problem-Based Learning: A Case Study". To Improve the Academy $370 \quad$ (1996): $75-91$. http:// digitalcommons.unl.edu/ podimproveacad/ 370 